\title{
The Impact of the Launch of Chin's CSI 300 Index Futures on the Volatility of CSI 300 Stock Index
}

\author{
Guo Mingyuan $^{1 *}$, Wang Lianxin ${ }^{1,2}$, Gao Shuang ${ }^{1}$ and Sun Xinran ${ }^{1}$ \\ ${ }^{1}$ College of Management and Economics, Tianjin University, Tianjin, \\ China, 300072 \\ ${ }^{2}$ Morgan Stanley Huaxin Fund Management Company Limited, Shenzhen, \\ China, 518000 \\ Corresponding Author*:leu2@163.com
}

\begin{abstract}
With the development of financial derivatives market, stock index futures has been a powerful tool in discovering price and hedging. It's critical whether stock index futures has significant effects on the volatility of the stock market. Based on the extensive literature review, we firstly estimate the daily volatility of the CSI 300 Index by realized bi-power variation. Then we use multiplicative error model to model the volatility of CSI 300 Index before and after CSI 300 index futures launched respectively. Then, we test whether the introduction of CSI 300 index futures have a significant impact on the volatility in stock market by using statistical methods. The research results show that the introduction of CSI 300 index futures reduces the volatility of CSI300 Stock Index apparently. As the representative of financial derivatives, CSI 300 index futures can effectively reduce the systemic risk of the stock market and it can also promote the maturity of China's stock markets.
\end{abstract}

Keywords: CSI 300 index futures; realized bi-power variation; multiplicative error model

\section{Introduction}

During the past 30 years, many scholars studied the relationship between stock index futures market and stock markets. They used different methods and did a great deal of empirical research. However, there are no consistent conclusions. We can broadly divide their conclusions into three categories: Firstly, the introduction of stock index futures increases stock market volatility; secondly, the introduction of stock index futures reduces stock market volatility; thirdly, the introduction of stock index futures has no impact on the volatility of stock market. 1.1 The introduction of stock index futures increases stock market volatility.

Kuserk and Cocke (1994) [1] analyzed the relationship between the US Dow Jones index and the stock index futures trading volume. They found that stock index futures attracted a lot of investors of arbitrage and hedging, which not only enlarged the scale and volume ofstock market but increased the volatility. K.Froot and A.perold (1995) [2] studied the relationship between NYSE index and NYSE index futures by GARCH model. The result showed that GARCH $(1,1)$ fits better than GARCH $(p, q)$. In addition, the introduction of NYSE stock index futures accelerated information flow about the NYSE index and improved the efficiency of the stock market. But it increased the volatility of the stock market. Koutmos and Tucker (1996) [3] studied the volatility spillover effect on stock market generated by the futures market. They used the bivariate EGARCH model and analyzed the S\&P 500 index except the data during 1987. They found the EGARCH model can effectively describe the characteristics of the asymmetric volatility effect 
aroused by positive and negative information. Meanwhile, they found that the stock index futures increased the volatility of stock index, but stock index had little impact on volatility of stock index futures. Ryoo and Smith G (2004) [4] studied the relationship between South Korean KOSPI 200 index and stock index futures. They discovered that the introduction of stock index futures reduced the persistence of impact on information and improved the effectiveness of stock market. At the same time, it also increased the volatility of stock market. Li Qiang (2007) [5] summarized extensive literature and found that the introduction of stock index futures can improve the information liquidity of the stock index, which led to the increasing of institutional investors and made traders change strategy, which would further cause huge volatility in stock price when the stock index futures contract expired.

\subsection{The Introduction of Stock Index Futures Reduces Stock Market Volatility}

Lee and Ohk (1992) [6] studied the relationship between Hang Deng Index (HSI) and Hang Deng Index futures by GARCH model. They chose the data of daily closing price from 1984 to 1988 and found that Hang Seng Index futures reduced the HIS's volatility. Similarly, Robison (1993) [7] chose the data of daily closing price of FTSE100 index and the stock index futures from 1980 to 1993 and got analogous conclusion. He found that the stock index futures reduced the volatility of stock market. Antoniou, Holmes and Phil (1995) [8] chose the daily closing price data of Germany's DAX index from 1987 to 1993. They studied the impact of the introduction of stock index futures on the stock market in Germany. The results showed that stock index futures still significantly reduced the volatility of stock market. Robert W. Faff and Michael D. McKenzie (2002) [9] chose the samples of seven representative countries' typical stock index (United States, Switzerland, Spain, Germany, Australia, Britain, Japan). They used seasonal adjusted GARCH model to do empirical research separately for each country and found that for Australia and Japan market, stock index futures reduced "the Tuesday effect"; for the United States and Switzerland market, stock index futures reduced "the Monday effect"; for Germany and the UK market, the introduction of stock index futures reduced the volatility in the stock market greatly. Liu Kaochang (2008) [10] improved the GARCH model and added a dummy variables into it. Then he did empirical research with the data of emerging market's futures and made the same conclusion that the introduction of stock index futures increased the volatility of stock index in short time, but in the long run it reduced the volatility. Fotis G (2013) [11] studied the influence the introduction of French and German stock index futures on the stock market with VECM-GARCH model. Their result showed that the introduction of stock index futures reduced stock market volatility both in French and German. Chen, Han (2013) [12] got a conclusion that the introduction of stock index futures reduced the volatility of the stock market. Han.C (2014) [13] found that the introduction of S\&P 500 index futures reduced the volatility of stock market. The reason was that the traders of stock index futures were mainly experienced and they had a large amount of information. Their trading in stock index futures could stabilize the stock market.

\subsection{The Introduction of Stock Index Futures Has No Impact on the Volatility of Stock Markets}

Bessembinder and Seguin (1992) [14] found that the futures trading activities were related to the life cycle of the futures contract and had nothing to do with the volatility of stock market. Meanwhile, they also proved that the stock index futures can improve the liquidity of the stock market. Pericli and Kourinos (1997) [15] chose the S\&P index as the sample and used nonparametric GARCH models to study the impact caused by stock index futures. The research suggested that the conditional or unconditional variance of the S\&P 500 index had no significant change except in October 1987, which showed the 
stock index futures caused no obvious impact on the stock market's volatility. Peng Lei and Xiao Tao (2004) [16] chose the daily return of Nikkei 225 index and studied the fluctuation of price index caused by Nikkei 225 stock index futures in the world's three largest exchanges. And the results showed that the Nikkei 225 stock index futures had little impact on the fluctuation of the stock market. Li Hua and Cheng Jing (2006) [17] also found that the Nikkei 225 stock index futures did not change the volatility of Nikkei 225 index. Debasish, Sathya (2009) [18] used the linear regression model and GARCH model to study the India Nifty index and found that the introduction of stock index futures had no impact on Nifty index volatility. In addition, Xu Shan (2011) [19] chose the sample of emerging market's index futures and used the improved GARCH model to do the empirical research. She found that the stock index futures reduced the fluctuation of the stock market in the short term for other emerging economies. However, with the development of stock index futures, it had little impact on the fluctuation of the stock market gradually.

In conclusion, the existing studies about the relationship between CSI 300 index futures market and the stock market mainly use daily data. With the development of computer technology, the acquisition of high-frequency data is possible. Volatility estimators computed with high-frequency data contain abundant information. It is necessary to study the impact of the introduction of CSI 300 index futures on the volatility of CSI 300 Stock Index by using high-frequency data. This paper aims to research whether the introduction of CSI 300 index futures have a significant impact on the volatility of CSI 300 index.

The remainder of the paper is organized as follows: In section 2, we introduce realized bi-power variation (RBV) put forward by Barndorff-Nielsen (2003) [20]. In section 3, we introduce multiplicative error model (MEM) which was proposed by Engle in 2002[21], which can model RBV. In section 4, we do empirical research.

\section{Realized Bi-Power Variation (RBV)}

Realized bi-power variation is defined as [20]:

$$
R B V_{t}^{[r, s]}=\left(\frac{h}{M}\right)^{1-(r+s) / 2} \sum_{j=1}^{M-1}\left|r_{j, h}\right|^{r}\left|r_{j+1, h}\right|^{s}
$$

Where, $r_{j+1, h}=\ln p_{j+1, h}-\ln p_{j, h}$ denotes the high-frequency returns in the $j^{t h}$ interval of day $h$.

Especially, when $r=s=1, R B V_{t}$ can defined as

$$
R B V_{t}^{[1,1]}=\sum_{j=1}^{M-1}\left|r_{j, h}\right|\left|r_{j+1, h}\right|
$$

where $R B V_{t}^{[1,1]}$ can be simplfied to $R B V_{t}$, that is the realized bi-power variation.

According to the theoretical derivation of Barndorff - Nielsen (2003) [20] and Shephard (2004) [22], when $r=s$, the equation (2) has the smallest variance. When $r+s=2, R B V_{t}^{[r, 2-r]}$ converges uniformly in probability to the integrated volatility. Thus, $\mathrm{RBV}$ have a more solid theoretical foundation and more extensive application prospect.

\section{Multiplicative Error Model (MEM)}

\subsection{MEM}

There are a lot of non-negative values of financial variables such as duration, volume, realized volatility, etc. To model non-negative values, there are two main traditional methods. The first one is to constraint the parameters of the model to satisfy the non-negative requirement. But this method greatly increases the difficulty of model estimation and can't guarantee the accuracy. The second one needs logarithmic treatment 
of non-negative values and then models the transformed data. This method has great disadvantages because of the existence of zero value in financial time series. MEM which were proposed by Engle in 2002 can model the non-negative data [21]. MEM can effectively solve non-negative data's modeling problem.

MEM is defined as:

$$
\begin{gathered}
v_{t} \mid I_{t-1}=\mu_{t} \varepsilon_{t}, \varepsilon_{t} \sim \text { i.i.d.f }(\varepsilon), t=1,2, \ldots, T \\
\mu_{t}=\omega+\sum_{i=1}^{p} \gamma_{i} v_{t-i}+\sum_{j=1}^{q} \omega_{j} \mu_{t-j}
\end{gathered}
$$

Where, $v_{t}$ is the non-negative variable, $I_{t-1}$ denotes the information set at time $\tau_{t-1}$, $\mu_{t}$ is the conditional mean of $v_{t}$, that is $E\left(v_{t} \mid I_{t-1}\right)=\mu_{t}$. Model coefficients satisfy the condition as $\gamma_{i}, \omega_{j} \geq 0, \omega>0$ and $\sum \gamma_{i}+\sum \omega_{i} \leq 1$. But the constraint of the parameters are not necessary suggested by Engle $(2002)^{[21]} . f(\varepsilon)$ is the probability density function of $\varepsilon_{t}$ which usually assumed to be subject to the standard exponential distribution, gamma distribution, standard weibull distribution. MEM can be estimated by pseudo maximum likelihood estimation method.

\subsection{Estimation of MEM}

A random variable follows exponential distribution with the parameters $\beta(\beta>0)$, if its probability density function is as follows:

$$
f(x \mid \beta)=\left\{\begin{array}{ccc}
\frac{1}{\beta} e^{-x / \beta}, \text { if } & x \geq 0, \\
0, & \text { if } \quad x<0
\end{array}\right.
$$

Such a distribution is expressed as $X \sim \exp (\beta)$. When the $\beta=1, \mathrm{X}$ follows standard exponential distribution. The conditional logarithmic likelihood function of EMEM model, whose residuals follow standard exponential distribution, is as follows:

$$
l\left(v \mid \theta, v_{t}\right)=\sum_{t=1}^{T} \ln \left(\frac{1}{v_{t}}\right)+\ln \left(\frac{v_{t}}{\mu_{t}}\right)-\frac{v_{t}}{\mu_{t}}
$$

Where, $\mu_{t}=\omega+\sum_{i=1}^{p} \gamma_{i} v_{t-i}+\sum_{j=1}^{q} \omega_{j} \mu_{t-j}, \theta=\left(\omega, \gamma_{1}, \ldots, \gamma_{p}, \omega_{1}, \ldots, \omega_{q}\right)^{\prime}, v=\left(v_{1}, \ldots, v_{T}\right)^{\prime}$.

A random variable follows weibull distribution with the parameters $\alpha, \beta(\alpha>0, \beta>0)$, if its probability density function is as follows:

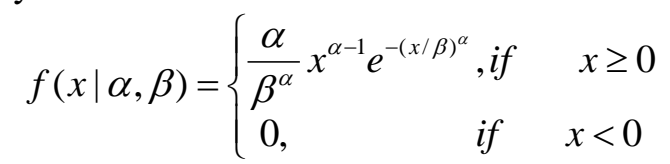

$\alpha$ and $\beta$ here are scale parameter and shape parameter of the distribution respectively. When $\alpha=1$, weibull distribution is simplified as exponential distribution. The expectation of Weibull distribution is as follows:

$$
E(X)=\beta \Gamma\left(1+\frac{1}{\alpha}\right)
$$

We define $Y=X /\left[\beta \Gamma\left(1+\frac{1}{\alpha}\right)\right]$, we can get $E(Y)=1$. Y follows standard Weibull distribution and the probability density function of $\mathrm{Y}$ is as follows: 


$$
f(y \mid \alpha)=\left\{\begin{array}{lrr}
\alpha\left[\Gamma\left(1+\frac{1}{\alpha}\right)\right]^{\alpha} y^{\alpha-1} \exp \left\{-\left[\Gamma\left(1+\frac{1}{\alpha}\right) y\right]^{\alpha}\right\}, \text { if } & y \geq 0 \\
0, & \text { if } & y<0
\end{array}\right.
$$

Because of the standardization, the scale parameter $\beta$ disappears. The conditional logarithmic likelihood function of WMEM model, whose residuals follow standard Weibull distribution is as follows:

$$
l\left(v \mid \theta, v_{t}\right)=\sum_{t=1}^{T} \alpha \ln \left[\Gamma\left(1+\frac{1}{\alpha}\right)\right]+\ln \left(\frac{\alpha}{v_{t}}\right)+\alpha \ln \left(\frac{v_{t}}{\mu_{t}}\right)-\left[\frac{\Gamma\left(1+\frac{1}{\alpha}\right) v_{t}}{\mu_{t}}\right]^{\alpha}
$$

Where, $\mu_{t}=\omega+\sum_{i=1}^{p} \gamma_{i} v_{t-i}+\sum_{j=1}^{q} \omega_{j} \mu_{t-j}, \theta=\left(\omega, \gamma_{1}, \ldots, \gamma_{p}, \omega_{1}, \ldots, \omega_{q}, \alpha\right)^{\prime}, \quad v=\left(v_{1}, \ldots, v_{T}\right)^{\prime}$.

A random variable follows generalized Gamma distribution with the parameters $\alpha, \beta$, $\kappa(\alpha>0, \beta>0, \kappa>0)$, if its probability density function is as follows:

$$
f(x \mid \alpha, \beta, \kappa)= \begin{cases}\frac{\alpha x^{\kappa \alpha-1}}{\beta^{\kappa \alpha} \Gamma(\kappa)} \exp \left[-\left(\frac{x}{\beta}\right)^{\alpha}\right], \text { if } & x \geq 0, \\ 0, & \text { if } \quad x<0\end{cases}
$$

Where, $\beta$ is scale parameter and $\alpha, \kappa$ here are shape parameters. When $\kappa=1$, generalized Gamma distribution is simplified as Weibull distribution. So, exponential distribution and Weibull distribution are special cases when generalized Gamma distribution parameters have specific values. The expectation of the generalized Gamma distribution is as follows:

$$
E(X)=\beta \Gamma\left(\kappa+\frac{1}{\alpha}\right) / \Gamma(\kappa)
$$

We define $Y=\lambda X / \beta$, where $\lambda=\Gamma(\kappa) / \Gamma\left(\kappa+\frac{1}{\alpha}\right)$, we can get $E(Y)=1$. Y follows standardized generalized Gamma distribution and its probability density function is as follows:

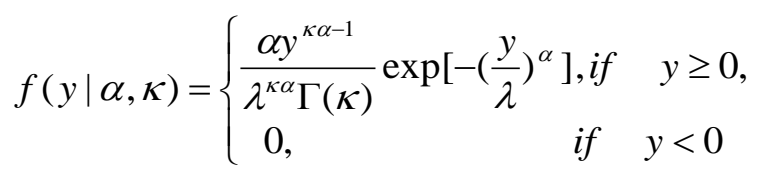

The conditional logarithmic likelihood function of GMEM, whose residuals follow standardized generalized Gamma distribution is as follows:

$$
l\left(v \mid \theta, v_{t}\right)=\sum_{t=1}^{T} \ln \left(\frac{\alpha}{\Gamma(\kappa)}\right)+(\kappa \alpha-1) \ln \left(v_{t}\right)-\kappa \alpha \ln \left(\lambda \mu_{t}\right)-\left[\frac{v_{t}}{\lambda \mu_{t}}\right]^{\alpha}
$$

Where, $\mu_{t}=\omega+\sum_{i=1}^{p} \gamma_{i} v_{t-i}+\sum_{j=1}^{q} \omega_{j} \mu_{t-j}, \theta=\left(\omega, \gamma_{1}, \ldots, \gamma_{p}, \omega_{1}, \ldots, \omega_{q}, \alpha, \kappa\right)^{\prime}$, $v=\left(v_{1}, \ldots, v_{T}\right)^{\prime}$.

\section{Empirical Analysis}

\subsection{Data}

We use five-minute frequency return data of China's CSI 300 stock index as sample from April 16, 2009 through April 15, 2011. We divide the time series into two parts to study the impact of the introduction of CSI 300 index futures on the CSI 300 index: from April 16, 2009 to April 16, 2010 and from April 16, 2010 to April 15, 2011. 


\subsection{Statistical Characteristics}

RBV of CSI 300 index are calculated by equation (2) before and after the introduction of CSI 300 index futures. Then Table 1 shows the statistical features of RBV before and after the introduction of CSI 300 index futures.

Table 1. The Statistical Features of RBV Before and After the Introduction of CSI 300 Index Futures

\begin{tabular}{r|cccccccc}
\hline & Mean & Max. & Min. & St.Dev. & $\begin{array}{c}\text { Skew } \\
\text { ness }\end{array}$ & $\begin{array}{c}\text { Kurto } \\
\text { sis }\end{array}$ & $\begin{array}{c}\text { JB } \\
\text { statistic }\end{array}$ & $\begin{array}{c}\text { p- } \\
\text { value }\end{array}$ \\
\hline $\begin{array}{r}\text { RBV } \\
\text { (before) }\end{array}$ & $1.4 \mathrm{e}-04$ & $1.6 \mathrm{e}-04$ & $1.1 \mathrm{e}-05$ & $1.5 \mathrm{e}-04$ & 5.04 & 45.77 & 19708. & 0 \\
$\begin{array}{r}\text { RBV } \\
\text { (after) }\end{array}$ & $1.0 \mathrm{e}-04$ & $4.9 \mathrm{e}-04$ & $2.0 \mathrm{e}-05$ & $7.7 \mathrm{e}-05$ & 2.31 & 9.51 & 640.46 & 0 \\
\hline
\end{tabular}

According to the data in Table 1, we can see that the mean of RBV of CSI 300 index after CSI 300 index futures were introduced is less than that of CSI 300 index before CSI 300 index futures were introduced. It means the introduction of CSI 300 index futures reduces the volatility in stock market. Meanwhile, the distribution of RBV after the introduction of CSI 300 index futures nearly follows normal distribution.

\subsection{Modeling RBV by MEM}

Many research shows that it is hard to determine the order when modeling in GARCH model. In most cases, only GARCH models with lower order are used, such as GARCH $(1,1)$ model, GARCH $(2,1)$ model, GARCH $(1,2)$ model, etc. GARCH $(1,1)$ and EGARCH $(1,1)$ model in the study of volatility are confirmed to have good fitting effect due to the low level $[23,24]$. Therefore, this paper uses MEM $(1,1)$ to model the two RBV time series before and after the introduction of CSI 300 index futures respectively.

As we mentioned above, stochastic error ${ }^{\varepsilon_{t}}$ can follow different distribution functions, such as standard exponential distribution, weibull distribution, gamma distribution, etc. We use MEM model with the three different stochastic error distribution, in order to choose the optimal MEM model for further empirical analysis. For convenience, we use EMEM, WMEM and GMEM model to denote standard exponential distribution, weibull distribution and gamma distribution respectively.

Firstly, we model the two RBV time series by $\operatorname{EMEM}(1,1)$ model. The results are shown in Table 2.

Table 2. Parameter Estimation Results of the Two RBV Time Series by EMEM $(1,1)$ Model with Constant Term

\begin{tabular}{c|ccccc}
\hline & $\begin{array}{c}\text { parameter } \\
\mathrm{S}\end{array}$ & $\begin{array}{l}\text { variable } \\
\text { value }\end{array}$ & $\begin{array}{c}\text { standar } \\
\text { d error }\end{array}$ & $\begin{array}{c}\mathrm{T}- \\
\text { statistic }\end{array}$ & P-value \\
\hline \multirow{3}{*}{ RBV(before) } & $\omega$ & 0.0947 & 0.0872 & 1.0867 & 0.2772 \\
& $\gamma_{1}$ & 0.4268 & 0.1779 & 2.3990 & 0.0164 \\
& $\omega_{1}$ & 0.5167 & 0.2131 & 2.4254 & 0.0153 \\
\hline \multirow{3}{*}{ RBV(after) } & $\omega$ & 0.0768 & 0.1365 & 0.5622 & 0.5740 \\
& $\gamma_{1}$ & 0.2890 & 0.2007 & 1.4399 & 0.1499 \\
& $\omega_{1}$ & 0.6359 & 0.2564 & 2.4800 & 0.0131 \\
\hline
\end{tabular}

Under the significance level of $1 \%$, the coefficient $\omega, \gamma_{1}$ and $\omega_{1}$ of EMEM model are not significant. It means $\operatorname{EMEM}(1,1)$ with constant term is not suitable to model the two RBV time series. 
In order to find out more suitable models, we use EMEM without constant term to estimate the parameters. The results as shown in Table 3.

Table 3. Parameter Estimation Results of the Two RBV Time Series by EMEM $(1,1)$ Model without Constant Term

\begin{tabular}{c|ccccc}
\hline & $\begin{array}{c}\text { paramete } \\
\text { rs }\end{array}$ & $\begin{array}{l}\text { variable } \\
\text { value }\end{array}$ & $\begin{array}{c}\text { standa } \\
\text { rd error }\end{array}$ & T-statistic & $\begin{array}{c}\text { P-valu } \\
\text { e }\end{array}$ \\
\hline $\begin{array}{c}\text { RBV(befor } \\
\text { e) }\end{array}$ & $\gamma_{1}$ & 0.4170 & 0.1412 & 2.9542 & 0.0031 \\
\hline \multirow{2}{*}{$\operatorname{RBV(after)}$} & $\omega_{1}$ & 0.6175 & 0.1282 & 4.8174 & 0.0000 \\
\hline & $\gamma_{1}$ & 0.2604 & 0.1367 & 1.9051 & 0.0057 \\
& $\omega_{1}$ & 0.7461 & 0.1213 & 6.1506 & 0.0000 \\
\hline
\end{tabular}

According to Table 3, the coefficient $\gamma_{1}$ and $\omega_{1}$ of EMEM model are significant. It means EMEM $(1,1)$ model without constant term are good-in-fitness. The estimation results are given in Table 4.

Table 4. Estimation Results of the Two RBV Time Series by EMEM $(1,1)$ Model without Constant Term

\begin{tabular}{c|c|c}
\hline & equation & $\begin{array}{c}\text { likelihood val } \\
\text { ues }\end{array}$ \\
\hline $\begin{array}{c}\text { RBV(befo } \\
\text { re) }\end{array}$ & $\mu_{t}=0.4170 R B V_{1}+0.6175 \mu_{t}$ & -1 \\
\hline $\begin{array}{c}\text { RBV(after } \\
)\end{array}$ & $\mu_{t}=0.2606 R B V_{2}+0.7461 \mu_{t}$ & -289.1406 \\
\hline
\end{tabular}

Then we model the two RBV time series by GMEM $(1,1)$ model. The estimation results are given in Table 5. According to Table 5, some parameters in GMEM $(1,1)$ model with constant term are not significant. Thus we estimate parameters of GEMEM (1, 1) model without constant term.

According to Table 6 , some parameters in $\operatorname{GMEM}(1,1)$ model without constant term are not significant under the significance level of $1 \%$. There is no suitable GMEM models to fit the two RBV time series. Finally, we model the two RBV time series by WMEM model. The estimation results are given in Table 7.

Table 5. Parameter Estimation Results of the Two RBV Time Series by GMEM $(1,1)$ Model with Constant Term

\begin{tabular}{l|cllcc}
\hline & parameters & variable value & $\begin{array}{l}\text { standard } \\
\text { error }\end{array}$ & T- statistic & P-value \\
\hline \multirow{5}{*}{ RBV(before) } & $\omega$ & 0.1874 & 0.0514 & 3.6474 & 0.0007 \\
& $\gamma_{1}$ & 0.3888 & 0.0722 & 5.3843 & 0.0000 \\
& $\omega_{1}$ & 0.4396 & 0.0971 & 4.5288 & 0.0000 \\
& $\alpha$ & 0.1408 & 0.1523 & 0.9246 & 0.3552 \\
& $\kappa$ & 164.5210 & 345.5195 & 0.4762 & 0.6340 \\
\hline \multirow{5}{*}{$\operatorname{RBV}$ (after) } & $\omega$ & 0.68128 & 0.0036 & 191.0405 & 0.0000 \\
& $\gamma_{1}$ & 0.55898 & 0.0024 & 235.3412 & 0.0032 \\
& $\omega_{1}$ & 0.9420 & 0.0001 & 16551.4538 & 0.0313 \\
& $\alpha$ & 4.1939 & 0.0011 & 3794.8807 & 0.2379 \\
& $\kappa$ & 116.4578 & 479.8658 & 0.1650 & 0.5849 \\
\hline
\end{tabular}


Table 6. Parameter Estimation Results of $\operatorname{GMEM}(1,1)$ Model without Constant Term

\begin{tabular}{c|ccccc}
\hline & $\begin{array}{c}\text { parameter } \\
\mathrm{s}\end{array}$ & $\begin{array}{l}\text { variable } \\
\text { value }\end{array}$ & $\begin{array}{l}\text { standard } \\
\text { error }\end{array}$ & $\begin{array}{c}\mathrm{T} \text { - } \\
\text { statistic }\end{array}$ & P-value \\
\hline \multirow{4}{*}{ RBV(before) } & $\gamma_{1}$ & 0.5427 & 0.0526 & 10.3123 & 0.0000 \\
& $\omega_{1}$ & 0.1284 & 0.0618 & 2.0776 & 0.0377 \\
& $\alpha$ & 0.1094 & 0.1815 & 0.6029 & 0.5466 \\
& $\kappa$ & 162.487 & 549.9199 & 0.2955 & 0.7676 \\
\hline \multirow{3}{*}{ RBV(after) } & $\gamma_{1}$ & 0.4447 & 0.0297 & 14.9501 & 0.0000 \\
& $\omega_{1}$ & 0.1739 & 0.0394 & 4.4161 & 0.0000 \\
& $\alpha$ & 0.1428 & 0.2320 & 0.6158 & 0.5380 \\
& $\kappa$ & 164.622 & 560.7956 & 0.2936 & 0.7691 \\
\hline
\end{tabular}

Table 7. Parameter Estimation Results of the Two RBV Time Series by WMEM $(1,1)$ Model with Constant Term

\begin{tabular}{c|ccccc}
\hline & parameters & $\begin{array}{c}\text { variabl } \\
\text { e value }\end{array}$ & $\begin{array}{c}\text { standar } \\
\text { d error }\end{array}$ & T-statistic & P-value \\
\hline \multirow{4}{*}{ RBV(before) } & $\omega$ & 0.1129 & 0.0452 & 2.4983 & 0.0125 \\
& $\gamma_{1}$ & 0.4765 & 0.1114 & 4.2785 & 0.0000 \\
& $\omega_{1}$ & 0.4640 & 0.1135 & 4.0883 & 0.0000 \\
& $\alpha$ & 1.4313 & 0.0546 & 26.2164 & 0.0000 \\
\hline \multirow{5}{*}{$\mathrm{RBV}$ (after) } & $\omega$ & 0.9025 & 0.2447 & 7.7747 & 0.0000 \\
& $\gamma_{1}$ & 0.0000 & 0.0945 & 3.9463 & 0.9998 \\
& $\omega_{1}$ & 0.9607 & 0.1941 & 4.9502 & 0.0000 \\
& $\alpha$ & 1.6302 & 0.0732 & 22.2800 & 0.0000 \\
\hline
\end{tabular}

According to Table 7 , some parameters in $\operatorname{WMEM}(1,1)$ model with constant term are not significant under the significance level of $1 \%$. Thus we estimates parameters in WEMEM $(1,1)$ model without constant term. The estimation results are given in Table 9. 
Table 8. Parameter Estimation Results by WMEM $(1,1)$ Model without Constant Term

\begin{tabular}{c|ccccc}
\hline & parameters & $\begin{array}{c}\text { variabl } \\
\text { e value }\end{array}$ & $\begin{array}{c}\text { standard } \\
\text { error }\end{array}$ & T-statistic & P-value \\
\hline \multirow{3}{*}{ RBV(before) } & $\gamma_{1}$ & 0.4758 & 0.0958 & 4.9658 & 0.0000 \\
& $\omega_{1}$ & 0.5733 & 0.0697 & 8.2224 & 0.0000 \\
& $\alpha$ & 1.4076 & 0.0571 & 24.6415 & 0.0000 \\
\hline \multirow{3}{*}{ RBV(after) } & $\gamma_{1}$ & 1.2514 & 0.0526 & 23.7739 & 0.0000 \\
& $\omega_{1}$ & 0.1758 & 0.0393 & 4.4732 & 0.0000 \\
& $\alpha$ & 1.6548 & 0.0989 & 16.7353 & 0.0000 \\
\hline
\end{tabular}

According to Table 8, the parameters in $\operatorname{WMEM}(1,1)$ model without constant term are significant under the significance level of $1 \%$. That means $\operatorname{WMEM}(1,1)$ model without constant term can fit the two RBV time series well. The estimation results are given in Table 9. Table 9. Estimation Results of the Two RBV Time Series by WMEM $(1,1)$
Model without Constant Term

\begin{tabular}{c|c|c}
\hline & equation & $\begin{array}{c}\text { likelihood val } \\
\text { ues }\end{array}$ \\
\hline $\begin{array}{c}\text { RBV } \\
\text { (RBV1,before })\end{array}$ & $\mu_{t}=0.4758 R B V_{1}+0.5733 \mu_{t}$ & -261.3728 \\
\hline $\begin{array}{c}\text { RBV } \\
(\text { RBV2,after })\end{array}$ & $\mu_{t}=1.2514 R B V_{2}+0.1758 \mu_{-1}$ & -195.1055 \\
\hline
\end{tabular}

We can compare the goodness of fit of different MEM models by the maximum likelihood values. The greater the likelihood value is, the better goodness of fit is. From the above empirical research, we conclude that WMEM $(1,1)$ without constant term is superior to other MEM $(1,1)$ models to fit the two RBV time series.

\subsection{The Change of Volatility of Chinese CSI 300 Index Before and After the Introduction of CSI 300 Index Futures}

We test whether the introduction of CSI 300 index futures promotes the stability of the stock market by studying the difference of the volatility before and after the introduction of CSI 300 index futures.

We define $\overline{\mu_{t}^{1}}$ and $\overline{\mu_{t}^{2}}$ as the mean of volatility estimated by WMEM $(1,1)$ model without constant term before and after the introduction of CSI 300 index futures respectively. Then we test whether $\overline{\mu_{t}^{1}}>\overline{\mu_{t}^{2}}$.

Null hypothesis is

$$
H O: \overline{\mu_{t}^{1}}=\overline{\mu_{t}^{2}}
$$

versus

$$
H 1: \overline{\mu_{t}^{1}}>\overline{\mu_{t}^{2}}
$$

The test results are shown below.

According to Table 10 , the mean of volatility obtained by $\operatorname{WMEM}(1,1)$ model without constant term reject null hypothesis. It shows that the mean of volatility after the introduction of CSI 300 index futures is less than that of before. Meanwhile, the introduction of CSI 300 index futures significantly stabilize the volatility of the stock market. 


\section{Table 10.Test Results of the Mean of Volatility Before and After the Introduction of CSI 300 Index Futures}

\begin{tabular}{|c|c|c|c|c|c|}
\hline \multicolumn{6}{|c|}{ Mean } \\
\hline & $\begin{array}{l}\text { observati } \\
\text { ons }\end{array}$ & sum & mean & \multicolumn{2}{|c|}{ variance } \\
\hline$\mu_{t}^{1}$ & 244 & 352.32 & 1.4439 & \multicolumn{2}{|c|}{1.0544} \\
\hline$\mu_{t}^{2}$ & 240 & 261.73 & 1.0906 & \multicolumn{2}{|c|}{0.0710} \\
\hline \multicolumn{6}{|c|}{ Variance analysis (ANOVA) } \\
\hline & $\begin{array}{l}\text { Degree of } \\
\text { Freedom }\end{array}$ & $\begin{array}{c}\text { Sum of } \\
\text { Squares of } \\
\text { Deviations }\end{array}$ & $\begin{array}{l}\text { mean } \\
\text { square }\end{array}$ & $\begin{array}{l}\text { F-val } \\
\text { ue }\end{array}$ & $\begin{array}{l}p \text {-va } \\
\text { lue }\end{array}$ \\
\hline $\begin{array}{c}\mathrm{S} \\
\mathrm{SA}\end{array}$ & 1 & 15.1083 & $\begin{array}{c}15.109 \\
4\end{array}$ & $\begin{array}{c}27.1 \\
063\end{array}$ & $00^{0.00}$ \\
\hline $\begin{array}{l}\mathrm{S} \\
\mathrm{SR}\end{array}$ & 482 & 273.1042 & 0.5668 & & \\
\hline $\begin{array}{l}\text { S } \\
\text { ST }\end{array}$ & 483 & 288.3039 & & & \\
\hline
\end{tabular}

\section{Conclusion}

This paper studies the impact of the introduction of CSI 300 index futures on the volatility of the CSI 300 Index in China. We use China's CSI 300 stock index's five-minute frequency return data as sample from April 16, 2009 through April 15, 2011. We firstly estimate the daily volatility of the CSI 300 Index by RBV. Then we use multiplicative error model (MEM) to fit the volatility of CSI 300 Index before and after the introduction of CSI 300 index futures respectively. We conclude that $\operatorname{WMEM}(1,1)$ model without constant term is significantly better than other MEM $(1,1)$ models to model the two RBV time series. Under the significance level of $1 \%$, we test the change of the mean of volatility before and after the introduction of CSI 300 index futures. We conclude that the introduction of CSI 300 index futures reduces the volatility of CSI300 Stock Index.

\section{Acknowledgments}

The authors gratefully acknowledge the financial support from the National Natural Science Foundation of China (No.70901055), the National Social Science Foundation of China (No: 14CTJ012), and the Independent Innovation Fund project of Tianjin University, China.

\section{References}

[1] G. J. Kuserk and P. R. Locke, "The Chicago Loop Tunnel Flood: Cash Pricing and Activity", Review of Futures Markets, vol. 13, pp. 115, (1994).

[2] K. A. Froot and A. F. Perold, "New Trading Practices and Short-Run Market Efficiency", Journal of Futures Markets, vol. 15, no. 7, (1995), pp. 731-765

[3] G. Koutmos and M. Tucker, "Temporal, Relationships and Dynamic Interactions between Spot and Futures Stock Markets", Journal of Futures Markets, vol. 16, no. 1, (1996), pp. 55-69.

[4] H. Ryoo and G. Smith, "The Impact of Stock Index Futures on the Korean Stock Marke", Applied Financial Economics, vol. 14, no. 4, (2004), pp. 243-251

[5] Q. Li, "The reviews of the impact of stock index futures on the stock market research", Wuhan Finance, no, 04, (2007), pp. 16-17. 
[6] S. B. Lee and K. Y. Ohk, "Does Futures Trading Increase Stock Market Volatility? The US, Japan, the UK and Hong Kong", Review of Futures Markets, vol. 11, no. 3, (1992), pp. 253-288.

[7] G Robinson, "The Effect of Futures Trading On Cash Market Volatility: Evidence From the London Stock Exchange", Bank of England, (1993).

[8] A. Antoniou and P. Holmes, "Futures Trading, Information and Spot Price Volatility: Evidence for the FTSE-100 Stock Index Futures Contract Using GARCH”, Journal of Banking \& Finance, vol. 19, no. 1, (1995), pp. 117-129.

[9] R. W. Faff and M. D. Mckenzie, "The Impact of Stock Index Futures Trading on Daily Returns Seasonality: A Multicountry Study*”, the Journal of Business, vol. 75, no. 1, (2002), pp. 95-125.

[10] K. Liu, S. Li and Y. Shu, "An Analysis of the Impact of the Stock Index Futures on the Market Fluctuations —-An Empirical Study Based on the KOSPI200 and TAIEX Stock Index Future", Journal of Hebei University (Philosophy and Social Science), no. 03, (2008), pp. 121-125.

[11] F. G. Kalantzis and N. T. Milonas, "Analyzing the Impact of Futures Trading On Spot Price Volatility: Evidence from the Spot Electricity Market in France and Germany”, Energy Economics, vol. 36, (2013), pp. $454-463$

[12] H. Chen, Q. Han and Y. Li, "Does Index Futures Trading Reduce Volatility in the Chinese Stock Market? A Panel Data Evaluation Approach", Journal of Futures Markets, vol. 33, no. 12, (2013), pp. 1167-1190.

[13] C. Han, "Impacts of Derivative Markets on Stock market Volatility and their Persistence", Available at SSRN, (2014).

[14] H. Bessembinder and P. J. Seguin, "Futures-Trading Activity and Stock Price Volatility", The Journal of Finance, vol. 47, no. 5, (1992), pp. 2015-2034.

[15] A. Pericli and G. Koutmos, "Index Futures and Options and Stock Market Volatility", Journal of Futures Markets, vol. 17, no. 8, (1997), pp. 957-974.

[16] L. Peng and T. Xiao, "The influence of stock index futures on the volatility of stock market research empirical analysis from Japan", Yunnan institute of finance and trade journals, no. 05, (2004), pp. 34-36.

[17] H. Li and J. Cheng, "The influence of stock index futures on the volatility of stock market researchempirical analysis from Japan", Finance and Economy, no. 02, (2006), pp. 81-83

[18] S. S. Debasish, "The Effect of Futures Trading On Spot-Price Volatility: Evidence for NSE Nifty Using GARCH", Journal of Risk Finance, vol. 10, no. 1, pp. 67-77, (2009).

[19] S. Xu, "The Influence of Stock Index Future on Stock markets Fluctuation_-Based on the study of stock index future of Asia-Pacific Emerging Markets", Journal of Shandong youth political college, no. 03, (2011), pp. 115-118.

[20] O. E. Barndorff-Nielsen and N. Shephard, "Realized Power Variation and Stochastic Volatility Models", Bernoulli, vol. 9, no. 2, (2003), pp. 243-265.

[21] R. Engle, "New Frontiers for ARCH Models", Journal of Applied Econometrics, vol. 17, no. 5, (2002), pp. 425-446.

[22] O. E. Barndorff-Nielsen and N. Shephard, "Power and Bipower Variation with Stochastic Volatility and Jumps", Journal of financial econometrics, vol. 2, no. 1, pp. 1-37, (2004).

[23] W. Du and H. H. Wang, "Price behavior in Chinese wheat futures market.China economic review", vol. 15 , no. 2, (2004), pp. 215-229.

[24] M. Sabbatini and O. Linton, "A GARCH model of the implied volatility of the Swiss market index from option prices”, International journal of forecasting, vol. 14, no. 2, (1998), pp. 199-213.

\section{Authors}

Guo Mingyuan, Associate professor of College of management and economics, Tianjin University, China. Email:leu2@163.com.

Wang Lianxin, Master of financial engineering of College of management and economics, Tianjin University, China; Analyst of Morgan Stanley Huaxin Fund Management Company Limited.

Gao Shuang, Master of technology economy and management of College of management and economics, Tianjin University, China.

Sun Xinran, graduate student of applied economics of College of management and economics, Tianjin University, China. 
International Journal of Control and Automation

Vol. 9, No. 11 (2016) 